Sergio E. Starkstein, Marcelo Morello

\section{Psychiatric and Cognitive Disorders in Parkinson's Disease}

Cambridge University Press, London 2002

239 pp.; GBP 47.50

ISBN 0-521-66305-9

This book offers a welcome and comprehensive account of the emotional problems that are encountered in Parkinson's disease: cognitive deficits, depression, anxiety, neuropsychological and psychiatric side effects of antiparkinsonian medications. There is a final chapter on treatment of psychiatric disorders in Parkinson's disease. The book is essential reading for physicians treating Parkinson's disease.

Michael Rutter, Eric Taylor (eds)

Child and Adolescent Psychiatry, ed 4

Blackwell Publishing, Oxford 2002

1224 pp.; GBP 99.50

ISBN 0-632-05361-5

This is the fourth edition of a leading textbook of child and adolescent psychiatry. This monumental work is divided into four parts: clinical assessment, influences on psychopathology, clinical syndromes, and approaches to treatment. Generally the chapters offer a balanced view of the field, particularly regarding biological versus psychosocial treatments. It is an essential reference book for a pediatric library.
Hugo A.H. D'haenen, Johan A. den Boer, Paul Willner (eds)

Biological Psychiatry, vol $1+2$ (set)

Wiley, New York 2002

1476 pp.; GBP 350.00

ISBN 0-471-49198-5

It is a comprehensive survey of biological psychiatry, which consists of two volumes. The first deals with basic principles (opened by two excellent chapters on conceptual issues by Berriors and Markovan and on measurements by Per Bech), cognitive disorders, substance-related disorders and schizophrenia. The second volume is concerned with mood, anxiety, eating and sleep disorders. The final section offers a stimulating view of personality disorders, particularly Cloninger's chapter (Functional Neuroanatomy and Brain Imaging of Personality and Its Disorders). A strong point of the volume is its truly international authorship. The quality of chapters is rather uneven, but they are all carefully referenced. The book is an excellent companion to psychopharmacology volumes.

Stirling Moorey, Steven Greer

\section{Cognitive Behaviour Therapy for People with Cancer}

Oxford University Press, Oxford 2002

220 pp.; GBP 24.95

ISBN 0-19-850866-2

It is an update of a 1989 book (Adjuvant Psychological Therapy for Patients with Cancer) by two leading investigators in the field of psycho-oncology. After a brief introduction on the psychology of cancer, the authors offer an overview of the modified cognitive behavior techniques which are suitable in the oncology setting. The book is very well written and may be appropriate not only for psychotherapists, but also for physicians who want to improve their psychosomatic skills.

\section{KARGER}

(C) 2003 S. Karger AG, Basel

Fax +4161306 1234 E-Mail karger@karger.ch www.karger.com 